\title{
MICROCYSTIN CHANGES AND PROTEOMIC RESPONSES OF MICROCYSTIS AERUGINOSA EXPOSED TO CADMIUM DURING COLONY FORMATION
}

\author{
BI, X. D. ${ }^{{ }^{*}}-$ DAI, W. $.^{*}-$ SUN, J. S. ${ }^{2}-$ JIA $\mathrm{N}^{3}$ \\ ${ }^{1}$ Key Laboratory of Aquatic-Ecology and Aquaculture of Tianjin, Department of Fisheries \\ Sciences, Tianjin Agricultural University \\ No. 22 Jinjing Road, Xiqing District, Tianjin 300384, China \\ ${ }^{2}$ Tianjin Key Laboratory of Animal and Plant Resistance, Tianjin Normal University \\ No. 393 Binshui West Road, Xiqing District, Tianjin 300387, China \\ (phone: +86-022-2376-6539; fax: +86-022-2376-6000) \\ ${ }^{3}$ Key Laboratory of Systems Bioengineering (Ministry of Education), School of Chemical \\ Engineering and Technology, Tianjin University \\ No. 92 Weijin Road, Nankai District, Tianjin 300372, China \\ (phone: +86-022-2740-3902; fax: +86-022-2740-3902) \\ *Corresponding authors \\ e-mail:yl80123@aliyun.com (X.D.Bi), daiweitj@126.com (W. Dai); phone: +86-022-2378- \\ 1299; fax: +86-022-2378-8970
}

(Received 1 ${ }^{\text {st }}$ Mar 2019; accepted 21 ${ }^{\text {st }}$ May 2019)

\begin{abstract}
Microcystis occurs as colonies in natural waters and always disaggregates into unicellular cells in the laboratory. Cadmium (Cd) could stimulate Microcystis colony formation in the laboratory. To elucidate the mechanism involved in cadmium-induced colony formation of Microcystis, microcystin (MC) changes and proteomic responses in M. aeruginosa treated with seven concentrations of $\mathrm{Cd}(0$, $0.0125,0.0250,0.0500,0.1000,0.2000$ and $0.4000 \mathrm{mg} / \mathrm{L}$ ) for $40 \mathrm{~h}$ were studied. The results showed that seven concentrations of $\mathrm{Cd}$ except $0.4000 \mathrm{mg} / \mathrm{L} \mathrm{Cd}$ could significantly induce colony formation $(P<0.05)$, and the Cd-induced colony-stimulating effects were accompanied with the increased intracellular MC-RR production. A total of 1170 proteins, including seven MC biosynthesis-related enzymes and seven polysaccharide biosynthesis-related enzymes, were identified using 2D-LC-MS/MS combined with isobaric tags for relative and absolute quantitation (iTRAQ). $0.4000 \mathrm{mg} / \mathrm{L} \mathrm{Cd}$ could downregulate all the identified enzymes involved in MC and polysaccharide biosynthesis while most of these enzymes were upregulated during Cd-induced colony formation. Cd might stimulate Microcystis colony formation via increasing the biosynthesis of $\mathrm{MC}$ and polysaccharide.
\end{abstract}

Keywords: cyanotoxin, polysaccharide, heavy metal ions, iTRAQ, Cyanobacteria colony

\section{Introduction}

Cyanobacteria blooms have been paid more and more attention all over the world for their toxic impacts on freshwater environments and human health (O'Neil et al., 2012). Microcystis is a common cyanobacterial genus forming blooms (Shen and Song, 2007). In natural freshwaters, Microcystis cells always aggregate into colonies (Zhu et al., 2016). Colony formation provides Microcystis with a competitive advantage in preventing zooplankton grazing, viral and bacterial attack (Yang and Kong, 2012). However, the mechanism involved in Microcystis colony formation remains poorly understood.

In laboratory cultures, Microcystis is hard to keep colonial phenotype and colonial Microcystis usually disaggregates into single cells or a few paired cells (Huisman et al., 
2018). Previous studies have identified that zooplankton grazing pressure (Yang et al., 2012), ultraviolet radiation (Sommaruga et al., 2008), heterotrophic bacteria cocultivation (Shen et al., 2011), low light intensities and temperatures (Li et al., 2013) could stimulate colony formation of Microcystis cultured in the laboratory. Moreover, we found that the contents of lead $(\mathrm{Pb})$, cadmium $(\mathrm{Cd})$, chromium $(\mathrm{Cr})$, aluminium $(\mathrm{Al})$, ferrum (Fe), and manganese ( $\mathrm{Mn})$ in Microcystis cell were significantly positive with the colony size in natural freshwaters (Bi et al., 2015). Cd(II) could promote Microcystis colony formation in an appropriate concentration range (Bi et al., 2016). Moreover, Gan et al. (2012) found that microcystin (MC, a typical cyanotoxin), supplementation in medium could enhance the size of Microcystis colony and depletion of MC could dramatically decrease colony size. Different from above external biotic and abiotic environmental factors, MC released by toxic Microcystis might act as an internal signal factor influencing the aggregation of Microcystis cells.

Proteomics, the large-scale analysis of proteins, can link the upstream genome and the downstream metabolome (Wilmes and Bond, 2009). Proteomic analysis has been widely applied in reflecting functional protein dynamic responses of cyanobacteria under stress (Alexova et al., 2016). According to the proteomic responses of $M$. aeruginosa to $\mathrm{N}$ or $\mathrm{P}$ starvation, Yue et al. (2015) found that $\mathrm{N}$ limitation enhanced the expression of several proteins relating to cellular $\mathrm{C}$ metabolism and fixation while $\mathrm{P}$ limitation downregulated the proteins involved in protein synthesis and the assimilation of $\mathrm{C}$ and $\mathrm{N}$. Proteomic response of $M$. aeruginosa revealed that long-term exposure of amoxicillin could affect the cellular biosynthesis process and the metabolism of nucleoside phosphate and carbohydrate (Liu et al., 2016).

To make clear how heavy metals affect colony formation of Microcystis, M. aeruginosa were treated with seven concentrations of $\mathrm{Cd}$ for $40 \mathrm{~h}$, and their changes in the colony formation, intracellular $\mathrm{MC}$ contents and proteomic responses were investigated. The results will help us reveal the impact of heavy metals on the breakout of Microcystis blooms in natural waters.

\section{Materials and methods}

\section{Algal culture conditions}

M. aeruginosa FACHB-905 was purchased from the Institute of Hydrobiology, Chinese Academy of Sciences. Algae were cultured in BG11 medium (without EDTA) under a L:D (12 h: $12 \mathrm{~h})$ cycle at a light intensity of $40 \mu \mathrm{mol} / \mathrm{m}^{2} / \mathrm{s}$ at $25^{\circ} \mathrm{C}$. Stock solution of $\mathrm{CdCl}_{2}$ (Merck, Germany) was added to algae cultured to the exponential phase, and the final concentrations of $\mathrm{Cd}$ were prepared as follows: 0.0125 (Cd_A), 0.0250 (Cd_B), 0.0500 (Cd_C), 0.1000 (Cd_D), 0.2000 (Cd_E) and $0.4000 \mathrm{mg} / \mathrm{L}$ $\left(\mathrm{Cd} \_\mathrm{F}\right)$. The culture without $\mathrm{Cd}$ was used as control group (CK). All groups were done in triplicate, and the initial density of $M$. aeruginosa was $5.2 \times 10^{6} \mathrm{ind} / \mathrm{L}$. After $40 \mathrm{~h}$, samples were taken from algal cultures to study changes in cell densities, colony numbers, MC content and proteomic analysis.

\section{Counting algal cell density and colony}

Algal cell density and colony were counted using a hemocytometer under microscope. Samples were collected $1 \mathrm{~cm}$ below the medium surface, and the flasks 
were shaken up slightly before sampling. Algal phenotype was classified as unicellular, two-cell aggregation and colony (aggregation of $\geq 3$ cells).

\section{Intracellular MC extraction and analysis}

Intracellular MC was extracted and measured according to the method of $\mathrm{Bi}$ et al. (2017) using high-performance liquid chromatography (SPD-M20A, Shimadzu, Japan) equipped with a Shim-Pack VP-ODS column $(250 \mathrm{~mm} \times 4.6 \mathrm{~mm})$. MC-RR was identified by its characteristic UV spectra and retention time, and spiked with purified standards of MC-RR (Sigma, USA).

\section{Proteomic analysis}

\section{Sampling, proteins extraction and iTRAQ labeling}

Samples were extracted with Lysis buffer (8 M Urea, $40 \mathrm{mM}$ Tris-HCl or TEAB, $\mathrm{pH}$ 8.5) containing $2 \mathrm{mM}$ EDTA and $1 \mathrm{mM}$ PMSF, and then added with $10 \mathrm{mM}$ DTT after being kept on ice for $5 \mathrm{~min}$, then were sonicated at $200 \mathrm{~W}$ for $1 \mathrm{~min}$. After centrifugation $\left(25000 \mathrm{~g}, 4{ }^{\circ} \mathrm{C}\right)$ for $20 \mathrm{~min}$, the supernatants obtained were incubated at $56{ }^{\circ} \mathrm{C}$ for $1 \mathrm{~h}$ and cooled to room temperature, then incubated with $55 \mathrm{mM}$ IAM (for alkylation) in darkness for $45 \mathrm{~min}$, and then centrifuged $\left(25000 \mathrm{~g}, 4^{\circ} \mathrm{C}\right)$ for $20 \mathrm{~min}$. Protein concentrations were quantified using Bradford method. The protein solution $(100 \mu \mathrm{g})$ with $8 \mathrm{M}$ urea was diluted 4 times with $100 \mathrm{mM}$ TEAB. For iTRAQ analysis, proteins were digested with Trypsin Gold (Promega, Madison, WI, USA) with a protein-to-trypsin ratio of $40: 1$ at $37{ }^{\circ} \mathrm{C}$ overnight, and peptides were desalted with a Strata X C18 column and vacuum-dried. The peptides were dissolved in $30 \mathrm{ul} 0.5 \mathrm{M}$ TEAB via vortexing. ITRAQ labeling reagents recovered to ambient were transferred and combined with proper samples. Peptide labeling was performed using ITRAQ Reagent 8-plex Kit. The labeled peptides with different reagents were combined and desalted with a Strata X C18 column and vacuum-dried, the above experimental method refers to Wiese et al. (2007).

\section{Peptide fractionation, HPLC, mass spectrometer detection}

After being reconstituted with buffer A $\left(5 \% \mathrm{ACN}, 95 \% \mathrm{H}_{2} \mathrm{O}\right.$, adjusting $\mathrm{pH}$ to 9.8 with ammonia) to $2 \mathrm{~mL}$, labeled peptides were fractioned using a Shimadzu LC-20AB HPLC pump system equipped with a high $\mathrm{pH}$ RP column at a flow rate of $1 \mathrm{~mL} / \mathrm{min}$ with a gradient of buffer $\mathrm{B}\left(5 \% \mathrm{H}_{2} \mathrm{O}, 95 \% \mathrm{ACN}\right.$, adjusting $\mathrm{pH}$ to 9.8 with ammonia): $5 \%$ for $10 \mathrm{~min}, 5-35 \%$ for $40 \mathrm{~min}, 35-95 \%$ for $1 \mathrm{~min}, 95 \%$ for $3 \mathrm{~min}, 95-5 \%$ within $1 \mathrm{~min}$ followed by $5 \%$ buffer for $10 \mathrm{~min}$. Chromatograms were recorded at $214 \mathrm{~nm}$, and fractions were collected at 1-min intervals. In total, 20 fractions were collected and vacuum-dried, dissolved in buffer $(2 \% \mathrm{ACN}, 0.1 \% \mathrm{FA}$ in water) and centrifuged at $20,000 \mathrm{~g}$ for $10 \mathrm{~min}$. Supernatants were loaded onto a C18 trap column using a LC20AD nano-HPLC instrument (Shimadzu, Kyoto, Japan) and eluted, then separated with an analytical C18 column packed in-house at a flow rate of $300 \mathrm{~nL} / \mathrm{min}$ with the following gradient of buffer $\left(2 \% \mathrm{H}_{2} \mathrm{O}\right.$ and $0.1 \% \mathrm{FA}$ in $\left.\mathrm{ACN}\right): 8-35 \%$ in $35 \mathrm{~min} ; 35-60 \%$ in $5 \mathrm{~min}, 80 \%$ for $5 \mathrm{~min}, 80-5 \%$ in $0.1 \mathrm{~min}$ and equilibrating for $10 \mathrm{~min}$. Data was acquired with a Triple TOF 5600 System equipped with a Nanospray III source (SCIEX, Framingham, MA, USA) and a pulled quartz tip emitter (New Objectives, Woburn, MA). This procedure was carried out by Beijing Genomics Institute 
(Shenzhen, China), the above experimental method refers to Olson et al. (2013) and Lyu et al. (2016).

Protein identification, quantification and data analysis

For an MS/MS Ions Search, each query represented a complete MS/MS spectrum. The common protein databases: NCBInr, SwissProt (Magrane and UniProt Consortium, 2011), and UniProt were used for protein identification. ITRAQ quantification was applied by BGI's IQuant (Wen et al., 2014). Proteins with 1.2-fold change and Q-value less than 0.05 were determined as differentially expressed protein. Genes were annotated by using BLAST* (Altschul and Gish, 1996) against Clusters of Orthologous Groups of proteins database (COG) (Tatusov et al., 2003) and Kyoto Encyclopedia of Genes and Genomes database (KEGG) (Kanehisa et al., 2006). We set Cd_A/CK, Cd_B/CK, Cd_C/CK, Cd_D/CK, Cd_E/CK, Cd_F/CK, as comparison group.

\section{Statistical analysis}

Data expressed as means \pm SD were subjected to one-way analysis of variance (SPSS ver. 10.0) to determine differences among groups, and least significant difference multiple-range test was used to determine significance differences $(P<0.05)$.

\section{Results and discussion}

Effects of Cd on the growth, colony formation and intracellular MC-RR content of M. aeruginosa

As shown in Figure 1A, with the increasing Cd concentrations, cell densities of $M$. aeruginosa increased first and then decreased, and the maximum cell density appeared in $M$. aeruginosa exposed to $0.0250 \mathrm{mg} / \mathrm{L} \mathrm{Cd}$. As compared to $\mathrm{CK}$, all tested concentrations of $\mathrm{Cd}$ except $0.4000 \mathrm{mg} / \mathrm{L} \mathrm{Cd}$ could significantly induce colony formation $(P<0.05)$, and $0.1000 \mathrm{mg} / \mathrm{L} \mathrm{Cd}$ showed the best inductive effects (Fig. 1B). Intracellular MC-RR contents of $M$. aeruginosa exposed to 0.0250, 0.0500, 0.1000 and $0.2000 \mathrm{mg} / \mathrm{L}$ of $\mathrm{Cd}$ increased significantly as compared to $\mathrm{CK}$ (Fig. 1C). Cd could contribute to $M$. aeruginosa cells aggregation, and the $\mathrm{Cd}$-induced colony-stimulating effects accompanied with the increased intracellular MC-RR contents. In our previous research, it was observed that the Microcystis colonies with smallest size in natural waters had the highest MC cellular production which decreased with the increasing colony size (Bi et al., 2017), suggesting toxic Microcystis might play a vital role in Microcystis colony formation via MCs production. Based on our above results, we speculated that $\mathrm{Cd}$ could increase the production of $\mathrm{MC}$ which acted as an internal signal stimulating the colony formation.

\section{Proteomic analysis of M. aeruginosa exposed to $C d$}

A total of 405114 spectrums were generated, 7766 peptides and 1170 protein were identified (Table A1). According to the distribution of COG classification, it was found that in $M$. aeruginosa FACHB-905 genome, the number of genes relating to energy production and conversion (C), amino acid transport and metabolism (E), carbohydrate transport and metabolism (G) and cell wall/membrane/envelope biogenesis (M) was more than that of other function related genes (Table A2). Among all the KEGG 
pathways, biosynthesis of secondary metabolites, antibiotics and amino acids accounted for $22.46 \%, 14.08 \%$ and $9.42 \%$, respectively (Table A3).
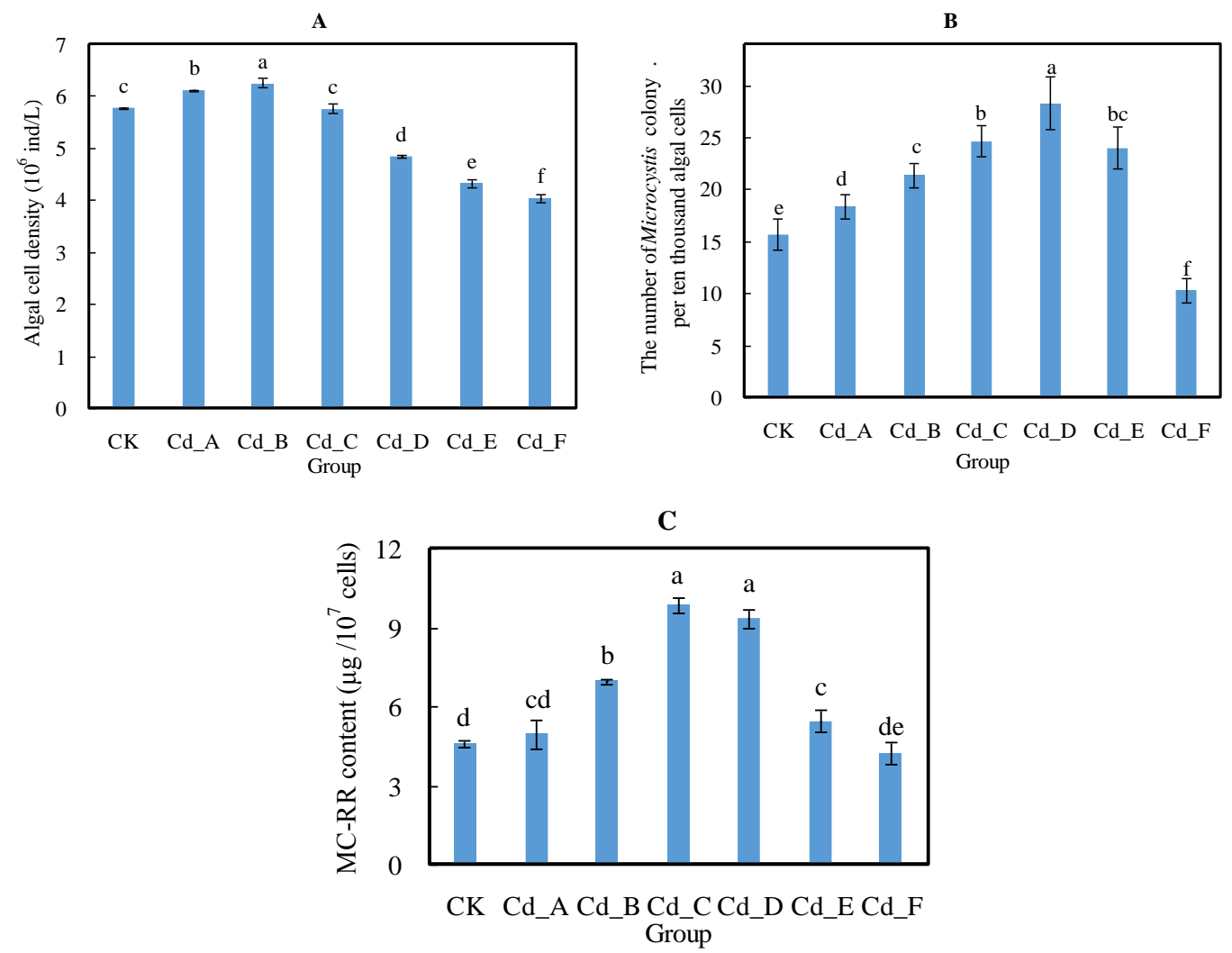

Figure 1. Effects of $C d$ on the growth (A), colony formation (B) and intracellular MC-RR content $(C)$ of $M$. aeruginosa

MCs are synthesized by a large, modular enzyme complex, including peptide synthetases McyA, McyB, and McyC, a polyketide synthase McyD, two hybrid enzymes (McyE and McyG) consisting of peptide synthetase and polyketide synthase modules, and enzymes putatively involved in the tailoring (McyJ, McyF, and McyI) and transport (McyH) of MCs (Tillett et al., 2000). As shown in Figure 2, a total of seven MC biosynthesis-related enzymes, including McyB, McyC, McyD, McyE, McyG, McyI, and McyJ were identified using proteomic analysis. Consistent with the changes in MC-RR, $0.4000 \mathrm{mg} / \mathrm{L} \mathrm{Cd}$ downregulated all these seven identified MC biosynthesisrelated enzymes. $0.050 \mathrm{mg} / \mathrm{L} \mathrm{Cd}$ upregulated all indentified $\mathrm{MC}$ biosynthesis-related enzymes except $\mathrm{McyG}$, and $0.0125 \mathrm{mg} / \mathrm{L} \mathrm{Cd}$ upregulated all indentified $\mathrm{MC}$ biosynthesis-related enzymes except McyJ. Other concentrations of $\mathrm{Cd}$ regulated MC biosynthesis-related enzymes to different degree. All tested concentrations of $\mathrm{Cd}$ except $0.4000 \mathrm{mg} / \mathrm{L} \mathrm{Cd}$ could upregulated the expression level of $\mathrm{McyC}$ while $\mathrm{McyD}$ expression of $M$. aeruginosa exposed to $0.0125-0.0500 \mathrm{mg} / \mathrm{L} \mathrm{Cd}$ was upregulated (Table A4).

Both soluble and total carbohydrates in colonial Microcystis cells and sheaths were significantly higher than those in disaggregated cells (Zhang et al., 2007). In colonial Microcystis, extracellular polysaccharides (EPS) were the main constituents of the 
sheaths relating to cell aggregation (Plude et al., 1991). Previous researches have proved that biotic and abiotic factors could stimulate polysaccharide production ( $\mathrm{Xu}$ et al., 2016; Yang et al., 2007). We also found that the contents of intracellular polysaccharide and bound extracellular polysaccharide in Cd-induced $M$. aeruginosa colony increased significantly, which could stimulate aggregation of algal cell and eventually promote colony formation ( $\mathrm{Bi}$ et al., 2016). Many genes were involved in polysaccharides synthesis pathway, such as $c a p D, c s a B, \operatorname{tagH}, r f b B$, and epsL (Thurlow et al., 2009). Proteomic analysis showed that all identified polysaccharide biosynthesis-relate enzymes were downregulated in $M$. aeruginosa exposed to $0.4000 \mathrm{mg} / \mathrm{L} \mathrm{Cd}$ which led to decreased colonies (Fig. 3). All concentrations of Cd except $0.4000 \mathrm{mg} / \mathrm{L}$ triggered upregulation of capsule biosynthesis protein CapD and sugar $\mathrm{ABC}$ transporter substratebinding protein while rfbB NAD-dependent dehydratase and lipid-A-disaccharide synthase of $M$. aeruginosa exposed to $0.0125-0.0500 \mathrm{mg} / \mathrm{L} \mathrm{Cd}$ were upregulated. These upregulated polysaccharide biosynthesis-relate enzymes might be responsible for $\mathrm{Cd}$ induced increase in polysaccharides.

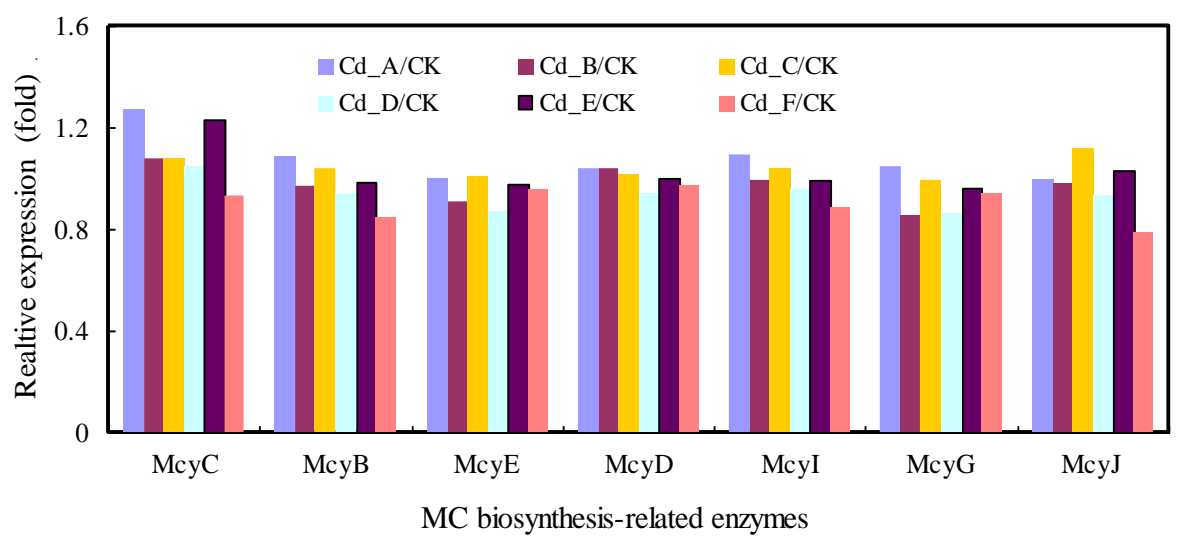

Figure 2. Cd-induced changes in the expressions of MC biosynthesis-relate enzymes of $M$. aeruginosa
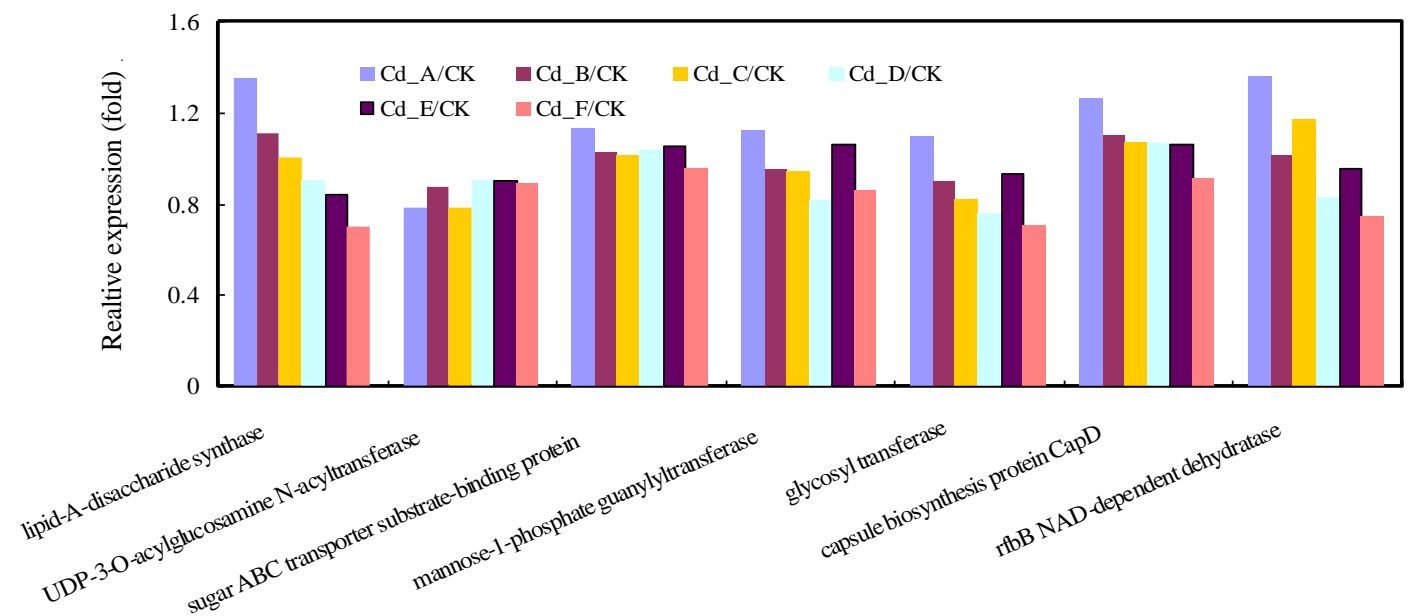

Polysaccharide biosynthesis-related enzymes

Figure 3. Cd-induced changes in the expressions of polysaccharide biosynthesis-relate enzymes of M. aeruginosa 
The strong competition advantages of $M$. aeruginosa in plankton system are based on its high photosynthetic activity (Amorim et al., 2017). Cd remarkably influenced the porphyrin and chlorophyll metabolism (Fig. 4), and photosynthesis (Fig. 5) in M. aeruginosa. 16 related proteins were upregulated or downregulated significantly in $M$. aeruginosa exposed to $0.4000 \mathrm{mg} / \mathrm{L} \mathrm{Cd}$. The expression level of heme oxygenase and ferredoxin: protochlorophyllide reductase increased in all groups, thus preventing or minimizing ROS-induced damages (Zhou et al., 2006). Furthermore, the expression level of magnesium-protoporphyrin IX monomethyl ester cyclase, radical SAM protein, glutamate-tRNA ligase, photosystem II extrinsic protein and ATP synthase increased by more than $27 \%$ in $M$. aeruginosa exposed to 0.0125 and $0.0500 \mathrm{mg} / \mathrm{L} \mathrm{Cd}$. The increased global effects on photosynthesis could help $M$. aeruginosa enhancing the carbon fixation and energy transfer, and thus promoting the synthesis of polysaccharides and colony formation. When the Cd contention was up to $0.0500 \mathrm{mg} / \mathrm{L}$, the expression level of allophycocyanin subunit beta/alpha and universal stress protein UspA increased by 1.5 fold as compared to the control group, thus protecting DNA against oxidative damage (Bhat and Madyastha, 2001).
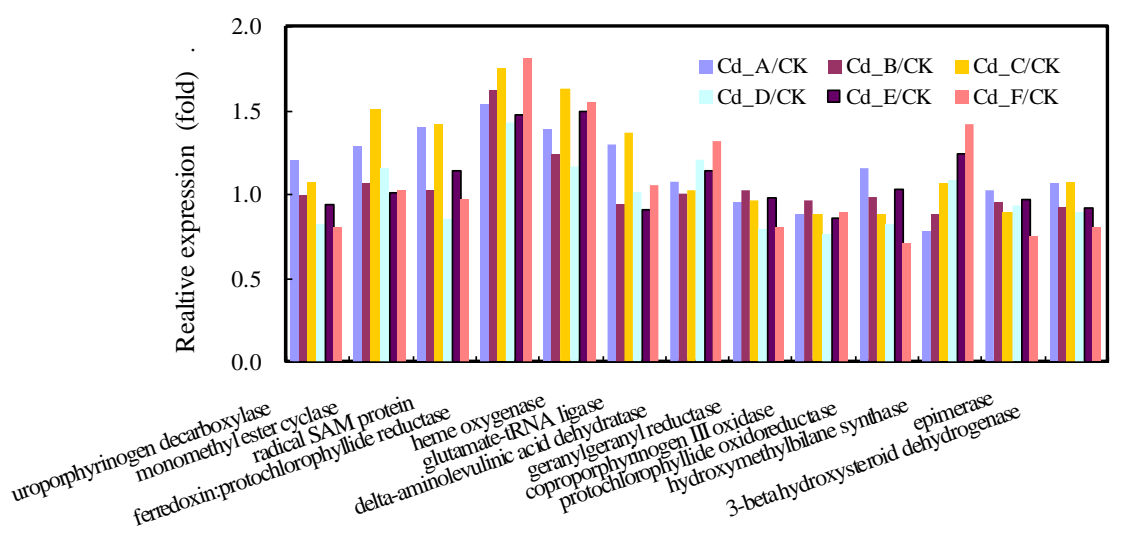

Enzymes involved in porphyrin and chlorophyll metabolism

Figure 4. Cd-induced changes in the expressions of enzymes involved in porphyrin and chlorophyll metabolism of M. aeruginosa

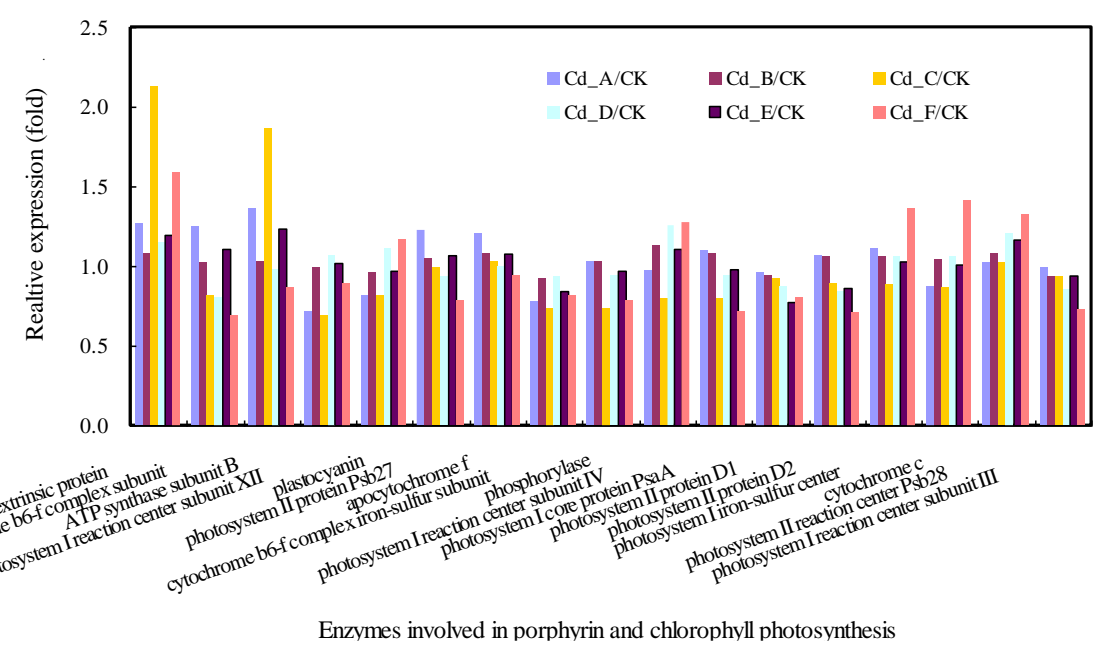

Figure 5. Cd-induced changes in the expressions of enzymes involved in porphyrin and chlorophyll photosynthesis of M. aeruginosa 
Consolidate all our findings about the effects of heavy metal ions on the Microcystis colony formation, we believe that Microcystis could bioaccumulate heavy metal ions, such as $\mathrm{Cd}$, in natural waters, and appropriate heavy metal ions enriched in Microcystis cell could promote the synthesis and secretion of polysaccharide and $\mathrm{MC}$ in $M$. aeruginosa by upregulated polysaccharide and MC biosynthesis-related enzymes. Heavy metal ions could increase Microcystis colony formation in natural waters with the assistance of low concentration of MC, which may act as an important internal signal stimulator.

\section{Conclusions}

Proper concentration of heavy metal ions could induce Microcystis colony formation. Heavy metal ions could increase Microcystis colony formation in natural waters with the assistance of low concentration of MC, which may act as an important internal signal stimulator. Further intensive study should be carried out to reveal the mechanism of synergistic reaction of MC and heavy metal ions.

Acknowledgements. This work is financially supported by National Natural Science Foundation of China (31772857) and Natural Science Foundation Grant of Tianjin (17JCYBJC29500, 18JCYBJC95900 and 16JCYBJC29900).

\section{REFERENCES}

[1] Alexova, R., Dang, T. C., Fujii, M., Raftery, M. J., Waite, T. D., Ferrari, B. C., Neilan, B. A. (2015): Specific global responses to $\mathrm{N}$ and $\mathrm{Fe}$ nutrition in toxic and non-toxic Microcystis aeruginosa. - Environmental Microbiology 18(2): 401-13.

[2] Altschul, S. F., Gish, W. (1996): Local alignment statistics. - Method in Enzymology 266: 460-480.

[3] Bhat, V. B., Madyastha, K. M. (2001): Scavenging of peroxynitrite by phycocyanin and phycocyanobilin from Spirulina platensis: protection against oxidative damage to DNA. - Biochemical and Biophysical Research Communications 285: 262-266.

[4] Bi, X. D., Dai, W., Zhang, S. L., Xing, K. Z., Zhang, X. F. (2015): Accumulation and distribution characteristics of heavy metals in different size Microcystis colonies from natural waters. - Fresenius Environmental Bulletin 24: 773-779.

[5] Bi, X. D., Yan, R., Li, F. X., Dai, W., Jiao, K. W., Zhou, Q. X., Liu, Q. (2016): Sequestration and distribution characteristics of Cd(II) by Microcystis aeruginosa and its role in colony formation. - BioMed Research International Article 9837598.

[6] Bi, X. D., Dai, W., Zhang, S. L., Dong, S. J., Zhang, D. J. (2017): Effects of toxic Microcystis genotypes on natural colony formation and mechanism involved. - Water Science and Technology 76(3-4): 885-894.

[7] Amorim, C. A., Ulisses, C., Moura, A. N. (2017): Biometric and physiological responses of Egeria densa Planch. cultivated with toxic and non-toxic strains of Microcystis. Aquatic Toxicology 191: 201-208.

[8] Gan, N. Q., Xiao, Y., Zhu, L., Wu, Z. X., Liu, J., Hu, C. L., Song, L. R. (2012): The role of microcystins in maintaining colonies of bloom-forming Microcystis spp.. Environmental Microbiology 14(3): 730-742.

[9] Huisman, J, Codd, G. A, Paerl, H. W, Ibelings, B. W, Verspagen, J. M. H, Visser, P. M. (2018): Cyanobacterial blooms. - Nature Reviews Microbiology 16(8): 471-483. 
[10] Kanehisa, M., Goto, S., Hattori, M., Aoki-Kinoshita, K. F., Itoh, M., Kawashima, S., Katayama, T. (2006): From genomics to chemical genomics: new developments in KEGG. - Nucleic Acids Research 34(suppl 1): D354-D357.

[11] Li, M., Zhu, W., Gao, L., Lu, L. (2013): Changes in extracellular polysaccharide content and morphology of Microcystis aeruginosa at different specific growth rates. - Journal of Applied Phycology 25(4): 1023-1030.

[12] Liu, Y., Chen, S., Zhang, J., Gao, B. Y. (2016): Growth, microcystin-production and proteomic responses of Microcystis aeruginosa under long-term exposure to amoxicillin. - Water Research 93: 141-152.

[13] Lyu, K., Meng, Q., Zhu, X., Dai, D., Zhang, L., Huang, Y., Yang, Z. (2016): Changes in iTRAQ-based proteomic profiling of the cladoceran Daphnia magna exposed to microcystin-producing and microcystin-free Microcystis aeruginosa. - Environment Science Technology 50(9): 4798-4807.

[14] Magrane, M., UniProt Consortium (2011): UniProt Knowledgebase: a hub of integrated protein data. - Database bar009. DOI: 10.1093/database/bar009.

[15] Olson, K. C., Chen, G., Lynch, C. J. (2013): Quantification of branched-chain keto acids in tissue by ultra fast liquid chromatography-mass spectrometry. - Analytical Biochemistry 439(2): 116-22.

[16] O’Neil, J. M., Davis, T. W. Burford, M. A., Gobler, C. J. (2012): The rise of harmful cyanobacteria blooms: The potential roles of eutrophication and climate change. Harmful Algae 14: 313-334.

[17] Omori, K., Datta, T., Amano, Y., Machida, M. (2019): Effects of different types of extracellular polysaccharides isolated from cyanobacterial blooms on the colony formation of unicellular Microcystis aeruginosa. - Environmental Science and Pollution Research 26(4): 3741-3750.

[18] Sommaruga, R., Chen, Y. W., Liu, Z. W. (2008): Multiple strategies of bloom-forming Microcystis to minimize damage by solar ultraviolet radiation in surface waters. Microbial Ecology, DOI: 10.1007/s00248-008-9425-4.

[19] Shen, H., Song, L. R. (2007): Comparative studies on physiological responses to phosphorus in two phenotypes of bloom-forming Microcystis. - Hydrobiologia 592: 475486.

[20] Shen, H., Niu, Y., Xie, P., Tao, M., Yang, X. (2011): Morphological and physiological changes in Microcystis aeruginosa as a result of interactions with heterotrophic bacteria. - Freshwater Biology 56: 1065-1080.

[21] Tatusov, R. L., Fedorova, N. D., Jackson, J. D., Jacobs, A. R., Kiryutin, B., Koonin, E. V., Krylov, D. M. (2003): The COG database: an updated version includes eukaryotes. BMC bioinformatics 4: 41.

[22] Thurlow, L. R., Thomas, V. C., Hancock, L. E. (2009): Capsular polysaccharide production in Enterococcus faecalis and contribution of CpsF to capsule serospecificity. Journal of Bacteriology 191(20): 6203-6210.

[23] Tillett, D., Dittmann, E., Erhard, M., von Döhren, H., Börner, T., Neilan, B. A. (2000): Structural organization of microcystin biosynthesis in Microcystis aeruginosa PCC7806: an integrated peptide-polyketide synthetase system. - Chemistry and Biology 7(10): 753764.

[24] Wen, B., Zhou, R., Feng, Q., Wang, Q., Wang, J., Liu, S. (2014): IQuant: An automated pipeline for quantitative proteomics based upon isobaric tags. - Proteomics 14(20): 22802285.

[25] Wiese, S., Reidegeld, K. A., Meyer, H. E., Warscheid, B. (2007): Protein labeling by iTRAQ: a new tool for quantitative mass spectrometry in proteome research. Proteomics 7(6): 1004.

[26] Wilmes, P., Bond, P. L. (2009): Microbial community proteomics: elucidating the catalysts and metabolic mechanisms that drive the Earth's biogeochemical cycles. Current Opinion in Microbiology 12(3): 310-317. 
[27] Xiao, M., Li, M., Reynolds, C. S. (2018): Colony formation in the cyanobacterium Microcystis. - Biological reviews 93(3): 1399-1420.

[28] Xu, F., Zhu, W., Xiao, M., Li, M. (2016): Interspecific variation in extracellular polysaccharide content and colony formation of Microcystis spp. cultured under different light intensities and temperatures. - Journal of Applied Phycology 28: 1533-1541.

[29] Yang, Z., Kong, F. X. (2012): Formation of large colonies: a defense mechanism of Microcystis aeruginosa under continuous grazing pressure by flagellate Ochromonas sp. - Journal of Limnology 171: 61-66.

[30] Yang, Z., Kong, F. X., Shi, X. L., Xing, P., Zhang, M. (2007): Effects of Daphniaassociated infochemicals on the morphology, polysaccharides content and PSII-efficiency in Scenedesmus obliquus. - International Review of Hydrobiology 92: 618-625.

[31] Yue, D., Peng, Y., Yin, Q., Xiao, L. (2015): Proteomic analysis of Microcystis aeruginosa in response to nitrogen and phosphorus starvation. - Journal of Applied Phycology 27: 1195-1204.

[32] Zhang, M., Kong, F., Tan, X., Yang, Z., Cao, H., Xing, P. (2007): Biochemical, morphological, and genetic variations in Microcystis aeruginosa due to colony disaggregation. World Journal of Microbiology and Biotechnology 23: 663-670.

[33] Zhou, W., Juneau, P., Qiu, B. (2006): Growth and photosynthetic responses of the bloomforming cyanobacterium Microcystis aeruginosa to elevated levels of cadmium. Chemosphere 65(10): 1738-1746.

[34] Zhu, W., Zhou, X. H., Chen, H. M., Gao, L., Xiao, M., Li, M. (2016): High nutrient concentration and temperature alleviated formation of large colonies of Microcystis: Evidence from field investigations and laboratory experiments. - Water Research 101(2016): 167-175.

\section{APPENDIX}

Tables $A 1$ and $A 4$ are electronic appendices.

Table A2. The COG distribution of all identified proteins in M. aeruginosa FACHB-905

\begin{tabular}{c|c|c}
\hline Abbreviation & Functional categories & Number \\
\hline B & Chromatin structure and dynamics & 1 \\
C & Energy production and conversion & 111 \\
D & Cell cycle control, cell division, chromosome partitioning & 21 \\
E & Amino acid transport and metabolism & 125 \\
F & Nucleotide transport and metabolism & 35 \\
G & Carbohydrate transport and metabolism & 83 \\
H & Coenzyme transport and metabolism & 70 \\
I & Lipid transport and metabolism & 34 \\
J & Translation, ribosomal structure and biogenesis & 104 \\
K & Transcription & 41 \\
L & Replication, recombination and repair & 38 \\
M & Cell wall/membrane/envelope biogenesis & 88 \\
N & Cell motility & 7 \\
O & Posttranslational modification, protein turnover, chaperones & 84 \\
P & Inorganic ion transport and metabolism & 61 \\
Q & Secondary metabolites biosynthesis, transport and catabolism & 46 \\
R & General function prediction only & 166 \\
S & Function unknown & 69 \\
T & Signal transduction mechanisms & 57 \\
U & Intracellular trafficking, secretion, and vesicular transport & 19 \\
V & Defense mechanisms & 15 \\
\hline
\end{tabular}


Table A3. The KEGG distribution of all identified proteins in M. aeruginosa FACHB-905

\begin{tabular}{|c|c|c|}
\hline No & Different proteins in annotated pathways & Number (percentage) \\
\hline 1 & Metabolic pathways & $411(42.55 \%)$ \\
\hline 2 & Biosynthesis of secondary metabolites & $217(22.46 \%)$ \\
\hline 3 & Biosynthesis of antibiotics & $136(14.08 \%)$ \\
\hline 4 & Microbial metabolism in diverse environments & $118(12.22 \%)$ \\
\hline 5 & Biosynthesis of amino acids & $91(9.42 \%)$ \\
\hline 6 & Carbon metabolism & $73(7.56 \%)$ \\
\hline 7 & Ribosome & $43(4.45 \%)$ \\
\hline 8 & Purine metabolism & $41(4.24 \%)$ \\
\hline 9 & Amino sugar and nucleotide sugar metabolism & $31(3.21 \%)$ \\
\hline 10 & Photosynthesis & $31(3.21 \%)$ \\
\hline 11 & $\mathrm{ABC}$ transporters & $30(3.11 \%)$ \\
\hline 12 & Oxidative phosphorylation & $29(3 \%)$ \\
\hline 13 & Glycolysis/Gluconeogenesis & $29(3 \%)$ \\
\hline 14 & Porphyrin and chlorophyll metabolism & $27(2.8 \%)$ \\
\hline 15 & Pyruvate metabolism & $26(2.69 \%)$ \\
\hline 16 & 2-Oxocarboxylic acid metabolism & $25(2.59 \%)$ \\
\hline 17 & Two-component system & $24(2.48 \%)$ \\
\hline 18 & Starch and sucrose metabolism & $24(2.48 \%)$ \\
\hline 19 & Aminoacyl-tRNA biosynthesis & $24(2.48 \%)$ \\
\hline 20 & Carbon fixation pathways in prokaryotes & $23(2.38 \%)$ \\
\hline 21 & Methane metabolism & $22(2.28 \%)$ \\
\hline 22 & Glyoxylate and dicarboxylate metabolism & $22(2.28 \%)$ \\
\hline 23 & Alanine, aspartate and glutamate metabolism & $22(2.28 \%)$ \\
\hline 24 & Pyrimidine metabolism & $22(2.28 \%)$ \\
\hline 25 & Glycine, serine and threonine metabolism & $21(2.17 \%)$ \\
\hline 26 & Fructose and mannose metabolism & $21(2.17 \%)$ \\
\hline 27 & RNA degradation & $21(2.17 \%)$ \\
\hline 28 & Cysteine and methionine metabolism & $20(2.07 \%)$ \\
\hline 29 & Pentose phosphate pathway & $19(1.97 \%)$ \\
\hline 30 & Carbon fixation in photosynthetic organisms & $19(1.97 \%)$ \\
\hline 31 & Photosynthesis - antenna proteins & $18(1.86 \%)$ \\
\hline 32 & Citrate cycle (TCA cycle) & $17(1.76 \%)$ \\
\hline 33 & Fatty acid metabolism & $17(1.76 \%)$ \\
\hline 34 & Fatty acid biosynthesis & $16(1.66 \%)$ \\
\hline 35 & Nitrogen metabolism & $16(1.66 \%)$ \\
\hline 36 & Glutathione metabolism & $14(1.45 \%)$ \\
\hline 37 & Valine, leucine and isoleucine biosynthesis & $14(1.45 \%)$ \\
\hline 38 & Arginine biosynthesis & $13(1.35 \%)$ \\
\hline 39 & Propanoate metabolism & $13(1.35 \%)$ \\
\hline 40 & Lysine biosynthesis & $12(1.24 \%)$ \\
\hline 41 & Phenylalanine, tyrosine and tryptophan biosynthesis & $12(1.24 \%)$ \\
\hline 42 & Butanoate metabolism & $12(1.24 \%)$ \\
\hline 43 & Arginine and proline metabolism & $12(1.24 \%)$ \\
\hline 44 & Histidine metabolism & $11(1.14 \%)$ \\
\hline 45 & Nonribosomal peptide structures & $11(1.14 \%)$ \\
\hline 46 & Sulfur metabolism & $10(1.04 \%)$ \\
\hline 47 & Streptomycin biosynthesis & $10(1.04 \%)$ \\
\hline 48 & C5-Branched dibasic acid metabolism & $10(1.04 \%)$ \\
\hline 49 & Terpenoid backbone biosynthesis & $10(1.04 \%)$ \\
\hline 50 & Ubiquinone and other terpenoid-quinone biosynthesis & $10(1.04 \%)$ \\
\hline 51 & Nicotinate and nicotinamide metabolism & $10(1.04 \%)$ \\
\hline 52 & Biotin metabolism & $10(1.04 \%)$ \\
\hline 53 & Galactose metabolism & $9(0.93 \%)$ \\
\hline
\end{tabular}




\begin{tabular}{|c|c|c|}
\hline 54 & Peptidoglycan biosynthesis & $9(0.93 \%)$ \\
\hline 55 & Mismatch repair & $9(0.93 \%)$ \\
\hline 56 & Pantothenate and CoA biosynthesis & $9(0.93 \%)$ \\
\hline 57 & One carbon pool by folate & $9(0.93 \%)$ \\
\hline 58 & Peroxisome & $8(0.83 \%)$ \\
\hline 59 & Central carbon metabolism in cancer & $8(0.83 \%)$ \\
\hline 60 & Cell cycle - Caulobacter & $8(0.83 \%)$ \\
\hline 61 & Bacterial secretion system & $8(0.83 \%)$ \\
\hline 62 & Tyrosine metabolism & $8(0.83 \%)$ \\
\hline 63 & Homologous recombination & $8(0.83 \%)$ \\
\hline 64 & Tuberculosis & $8(0.83 \%)$ \\
\hline 65 & DNA replication & $8(0.83 \%)$ \\
\hline 66 & Protein export & $7(0.72 \%)$ \\
\hline 67 & Glucagon signaling pathway & $7(0.72 \%)$ \\
\hline 68 & Nucleotide excision repair & $7(0.72 \%)$ \\
\hline 69 & Cationic antimicrobial peptide (CAMP) resistance & $7(0.72 \%)$ \\
\hline 70 & Carotenoid biosynthesis & $7(0.72 \%)$ \\
\hline 71 & Biosynthesis of unsaturated fatty acids & $6(0.62 \%)$ \\
\hline 72 & Legionellosis & $6(0.62 \%)$ \\
\hline 73 & Fatty acid degradation & $6(0.62 \%)$ \\
\hline 74 & Folate biosynthesis & $6(0.62 \%)$ \\
\hline 75 & Thiamine metabolism & $6(0.62 \%)$ \\
\hline 76 & Degradation of aromatic compounds & $5(0.52 \%)$ \\
\hline 77 & Drug metabolism - other enzymes & $5(0.52 \%)$ \\
\hline 78 & Selenocompound metabolism & $5(0.52 \%)$ \\
\hline 79 & Monobactam biosynthesis & $5(0.52 \%)$ \\
\hline 80 & Valine, leucine and isoleucine degradation & $5(0.52 \%)$ \\
\hline 81 & Base excision repair & $5(0.52 \%)$ \\
\hline 82 & Drug metabolism - cytochrome P450 & $5(0.52 \%)$ \\
\hline 83 & Inositol phosphate metabolism & $5(0.52 \%)$ \\
\hline 84 & Phenylalanine metabolism & $5(0.52 \%)$ \\
\hline 85 & Cyanoamino acid metabolism & $5(0.52 \%)$ \\
\hline 86 & Vitamin B6 metabolism & $5(0.52 \%)$ \\
\hline 87 & Salmonella infection & $5(0.52 \%)$ \\
\hline 88 & Type I polyketide structures & $4(0.41 \%)$ \\
\hline 89 & Protein processing in endoplasmic reticulum & $4(0.41 \%)$ \\
\hline 90 & Chemical carcinogenesis & $4(0.41 \%)$ \\
\hline 91 & Metabolism of xenobiotics by cytochrome $\mathrm{P} 450$ & $4(0.41 \%)$ \\
\hline 92 & Aminobenzoate degradation & $4(0.41 \%)$ \\
\hline 93 & Tryptophan metabolism & $4(0.41 \%)$ \\
\hline 94 & Polyketide sugar unit biosynthesis & $4(0.41 \%)$ \\
\hline 95 & Glycerophospholipid metabolism & $4(0.41 \%)$ \\
\hline 96 & Sulfur relay system & $4(0.41 \%)$ \\
\hline 97 & Riboflavin metabolism & $4(0.41 \%)$ \\
\hline 98 & Pentose and glucuronate interconversions & $4(0.41 \%)$ \\
\hline 99 & Insulin signaling pathway & $4(0.41 \%)$ \\
\hline 100 & Chloroalkane and chloroalkene degradation & $4(0.41 \%)$ \\
\hline 101 & HIF-1 signaling pathway & $4(0.41 \%)$ \\
\hline 102 & GABAergic synapse & $4(0.41 \%)$ \\
\hline 103 & Biosynthesis of ansamycins & $4(0.41 \%)$ \\
\hline 104 & Glycerolipid metabolism & $4(0.41 \%)$ \\
\hline 105 & RNA polymerase & $4(0.41 \%)$ \\
\hline 106 & Tetracycline biosynthesis & $4(0.41 \%)$ \\
\hline 107 & Lipopolysaccharide biosynthesis & $3(0.31 \%)$ \\
\hline 108 & AMPK signaling pathway & $3(0.31 \%)$ \\
\hline
\end{tabular}




\begin{tabular}{|c|c|c|}
\hline 109 & Pathways in cancer & $3(0.31 \%)$ \\
\hline 110 & Huntington's disease & $3(0.31 \%)$ \\
\hline 111 & Viral carcinogenesis & $3(0.31 \%)$ \\
\hline 112 & Toluene degradation & $3(0.31 \%)$ \\
\hline 113 & Type II diabetes mellitus & $3(0.31 \%)$ \\
\hline 114 & Biosynthesis of siderophore group nonribosomal peptides & $3(0.31 \%)$ \\
\hline 115 & Chlorocyclohexane and chlorobenzene degradation & $3(0.31 \%)$ \\
\hline 116 & Fluorobenzoate degradation & $2(0.21 \%)$ \\
\hline 117 & PPAR signaling pathway & $2(0.21 \%)$ \\
\hline 118 & Mineral absorption & $2(0.21 \%)$ \\
\hline 119 & Limonene and pinene degradation & $2(0.21 \%)$ \\
\hline 120 & N-Glycan biosynthesis & $2(0.21 \%)$ \\
\hline 121 & Taurine and hypotaurine metabolism & $2(0.21 \%)$ \\
\hline 122 & Synaptic vesicle cycle & $2(0.21 \%)$ \\
\hline 123 & Sphingolipid metabolism & $2(0.21 \%)$ \\
\hline 124 & Isoquinoline alkaloid biosynthesis & $2(0.21 \%)$ \\
\hline 125 & Stilbenoid, diarylheptanoid and gingerol biosynthesis & $2(0.21 \%)$ \\
\hline 126 & Phosphatidylinositol signaling system & $2(0.21 \%)$ \\
\hline 127 & Insulin resistance & $2(0.21 \%)$ \\
\hline 128 & Naphthalene degradation & $2(0.21 \%)$ \\
\hline 129 & Benzoate degradation & $2(0.21 \%)$ \\
\hline 130 & Atrazine degradation & $2(0.21 \%)$ \\
\hline 131 & FoxO signaling pathway & $2(0.21 \%)$ \\
\hline 132 & Lysine degradation & $2(0.21 \%)$ \\
\hline 133 & Tropane, piperidine and pyridine alkaloid biosynthesis & $2(0.21 \%)$ \\
\hline 134 & RNA transport & $2(0.21 \%)$ \\
\hline 135 & Bisphenol degradation & $2(0.21 \%)$ \\
\hline 136 & Adipocytokine signaling pathway & $2(0.21 \%)$ \\
\hline 137 & Alzheimer's disease & $2(0.21 \%)$ \\
\hline 138 & Phenylpropanoid biosynthesis & $2(0.21 \%)$ \\
\hline 139 & Vasopressin-regulated water reabsorption & $2(0.21 \%)$ \\
\hline 140 & Meiosis - yeast & $2(0.21 \%)$ \\
\hline 141 & Type I diabetes mellitus & $2(0.21 \%)$ \\
\hline 142 & Glutamatergic synapse & $2(0.21 \%)$ \\
\hline 143 & Novobiocin biosynthesis & $2(0.21 \%)$ \\
\hline 144 & Vancomycin resistance & $2(0.21 \%)$ \\
\hline 145 & Endocytosis & $1(0.1 \%)$ \\
\hline 146 & Flavonoid biosynthesis & $1(0.1 \%)$ \\
\hline 147 & Isoflavonoid biosynthesis & $1(0.1 \%)$ \\
\hline 148 & Renal cell carcinoma & $1(0.1 \%)$ \\
\hline 149 & beta-Lactam resistance & $1(0.1 \%)$ \\
\hline 150 & Polycyclic aromatic hydrocarbon degradation & $1(0.1 \%)$ \\
\hline 151 & Linoleic acid metabolism & $1(0.1 \%)$ \\
\hline 152 & Nitrotoluene degradation & $1(0.1 \%)$ \\
\hline 153 & Influenza A & $1(0.1 \%)$ \\
\hline 154 & Hepatitis B & $1(0.1 \%)$ \\
\hline 155 & NOD-like receptor signaling pathway & $1(0.1 \%)$ \\
\hline 156 & mRNA surveillance pathway & $1(0.1 \%)$ \\
\hline 157 & PI3K-Akt signaling pathway & $1(0.1 \%)$ \\
\hline 158 & Cocaine addiction & $1(0.1 \%)$ \\
\hline 159 & Thyroid hormone synthesis & $1(0.1 \%)$ \\
\hline 160 & Biosynthesis of type II polyketide products & $1(0.1 \%)$ \\
\hline 161 & Toxoplasmosis & $1(0.1 \%)$ \\
\hline 162 & Styrene degradation & $1(0.1 \%)$ \\
\hline 163 & D-Glutamine and D-glutamate metabolism & $1(0.1 \%)$ \\
\hline
\end{tabular}




\begin{tabular}{|c|c|c|}
\hline 164 & p53 signaling pathway & $1(0.1 \%)$ \\
\hline 165 & Plant-pathogen interaction & $1(0.1 \%)$ \\
\hline 166 & beta-Alanine metabolism & $1(0.1 \%)$ \\
\hline 167 & Retinol metabolism & $1(0.1 \%)$ \\
\hline 168 & Ethylbenzene degradation & $1(0.1 \%)$ \\
\hline 169 & D-Alanine metabolism & $1(0.1 \%)$ \\
\hline 170 & Parkinson's disease & $1(0.1 \%)$ \\
\hline 171 & Non-alcoholic fatty liver disease (NAFLD) & $1(0.1 \%)$ \\
\hline 172 & Prostate cancer & $1(0.1 \%)$ \\
\hline 173 & Viral myocarditis & $1(0.1 \%)$ \\
\hline 174 & Biosynthesis of 12-, 14- and 16-membered macrolides & $1(0.1 \%)$ \\
\hline 175 & Colorectal cancer & $1(0.1 \%)$ \\
\hline 176 & Alcoholism & $1(0.1 \%)$ \\
\hline 177 & Amphetamine addiction & $1(0.1 \%)$ \\
\hline 178 & Serotonergic synapse & $1(0.1 \%)$ \\
\hline 179 & Steroid hormone biosynthesis & $1(0.1 \%)$ \\
\hline 180 & Phosphonate and phosphinate metabolism & $1(0.1 \%)$ \\
\hline 181 & Other glycan degradation & $1(0.1 \%)$ \\
\hline 182 & Glycosaminoglycan biosynthesis - chondroitin sulfate/dermatan sulfate & $1(0.1 \%)$ \\
\hline 183 & Ascorbate and aldarate metabolism & $1(0.1 \%)$ \\
\hline 184 & Epithelial cell signaling in Helicobacter pylori infection & $1(0.1 \%)$ \\
\hline 185 & Small cell lung cancer & $1(0.1 \%)$ \\
\hline 186 & Progesterone-mediated oocyte maturation & $1(0.1 \%)$ \\
\hline 187 & Synthesis and degradation of ketone bodies & $1(0.1 \%)$ \\
\hline 188 & Apoptosis & $1(0.1 \%)$ \\
\hline 189 & Amyotrophic lateral sclerosis (ALS) & $1(0.1 \%)$ \\
\hline 190 & Renin-angiotensin system & $1(0.1 \%)$ \\
\hline 191 & Carbapenem biosynthesis & $1(0.1 \%)$ \\
\hline 192 & Herpes simplex infection & $1(0.1 \%)$ \\
\hline 193 & Antigen processing and presentation & $1(0.1 \%)$ \\
\hline 194 & Dopaminergic synapse & $1(0.1 \%)$ \\
\hline 195 & Estrogen signaling pathway & $1(0.1 \%)$ \\
\hline 196 & Butirosin and neomycin biosynthesis & $1(0.1 \%)$ \\
\hline 197 & Biosynthesis of vancomycin group antibiotics & $1(0.1 \%)$ \\
\hline
\end{tabular}

